\title{
"Modificación de la respuesta hidrológica en avenidas torrenciales ante los cambios de usos del suelo en una cuenca de montaña (Portainé, Pirineo leridano)"
}

\author{
De las Heras, A \\ Escuela Técnica Superior de Ingeniería de Montes, Forestal y del Medio Natural, \\ c/ José Antonio Nováis 12D, 28040, Madrid
}

*Autor para correspondencia: alvarodelasheras@hotmail.com

\section{Resumen}

El presente trabajo se centra en el estudio de los cambios producidos en la respuesta hidrológica de una cuenca de alta montaña, por las actividades antrópicas y cambios en los usos del suelo desarrollados en la misma en el último siglo.

La construcción de una estación de esquí en el barranco de Portainé, situado en los Pirineos Orientales (Lleida, España), ha desencadenado fenómenos de movimientos de ladera, procesos erosivos y deposición de grandes cantidades de materiales, arrastrados principalmente en eventos de precipitaciones intensas. Esto ha ido produciendo cuantiosos desperfectos en las instalaciones, y elevados costes de reparación.

Para estudiar cómo ha cambiado la respuesta hidrológica de la cabecera de la cuenca, se crearon y combinaron diferentes modelos mediante sistemas de información geográfica (SIG), para las situaciones anteriores y posteriores a la construcción de la estación de esquí. Estos modelos de combinaron con el programa de simulación hidrológica HEC-HMS para simular la transformación de las lluvias en caudales punta para los diferentes años estudiados.

Se obtuvieron resultados significativos, principalmente en la zona de la estación de esquí, aumentando sus caudales punta hasta un 26\%, con periodos de retorno bajos, respecto a la situación anterior a su construcción. Del mismo modo se observaron cambios de hasta un $15 \%$ en su confluencia con el barranco de Reguerals.

Se deduce que los cambios producidos en la cabecera del barranco de Portainé sí han tenido una influencia significativa en el aumento de la frecuencia de "debris" como consecuencia del aumento de magnitud de los caudales punta.

Palabras clave: debris, usos del suelo, hidrología, Hec-Hms, SIG. 


\section{Introducción}

\subsection{Introducción a la temática}

Las avenidas torrenciales se pueden definir como: "corrientes de agua impetuosas que sobreviene en poco tiempo". Constituyen las catástrofes naturales con mayor impacto socio-económico, afectando a las actividades agrarias, industriales y comerciales, infraestructuras y servicios, produciéndose una gran cantidad de pérdidas económicas, que según estimaciones realizadas por el Instituto Geológico y Minero de España (IGME), serían de aproximadamente 2 millones de euros cada día (Llorente Isidro, M. et al., 2008; Ferrer et al., 2004). Desgraciadamente estos eventos también han tenido asociados la pérdida de numerosas vidas humanas.

En España, la orografía accidentada del territorio, y el carácter mediterráneo del clima produce un elevado impacto de las avenidas torrenciales, las cuáles por lo general, vienen acompañadas de un abundante arrastre de materiales sólidos, aumentando considerablemente la peligrosidad asociada a este tipo de avenidas (Bodoque et al., 2006).

Con el fin de prevenir estos eventos y sus consecuencias, se emplean diferentes técnicas, como son los métodos hidrológicos, hidráulicos, históricos y geológicos (Díez-Herrero, 2002).

Los métodos hidrológicos permiten la simulación del proceso de transformación de las precipitaciones en escorrentía, pudiendo analizar el carácter torrencial de los ríos. Mediante herramientas informáticas como los sistemas de información geográfica (SIG), y su combinación con programas de modelación hidrológicos como HEC-HMS (Hydrologic Modeling System - Hydrologic Engineering Center), han permitido un avance en la sistematización y simulación de estos eventos (Llorente et al., 2009).

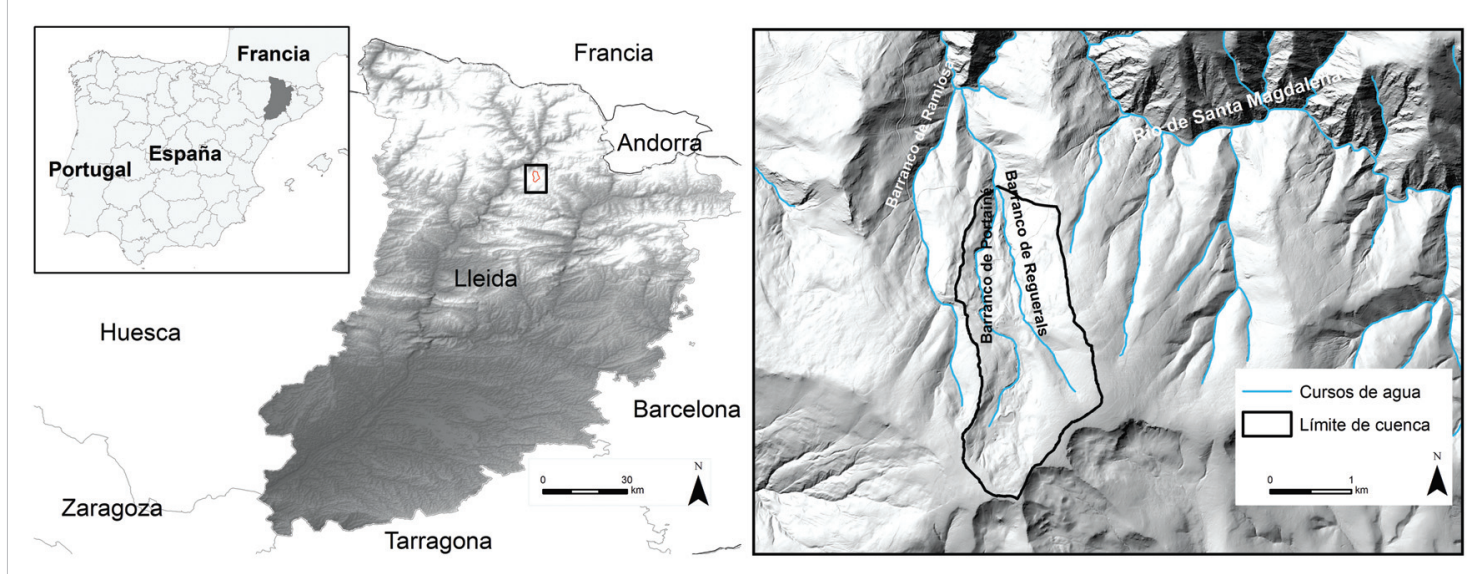

Figura 1. Localización de la zona de estudio de Portainé (Lleida, España). 
El barranco de Portainé es un torrente de alta montaña situado en los Pirineos Orientales, al norte de la provincia de Lleida (Figura 1). Su cuenca hidrográfica tiene su cota máxima en la Torreta del Orri a 2439 m.s.n.m., y desemboca en el río Romadriú (Santa Magdalena), con su cota mínima de 950 m.s.n.m. Tiene un fuerte carácter torrencial, aún más destacado en verano cuando se suceden fuertes llu-

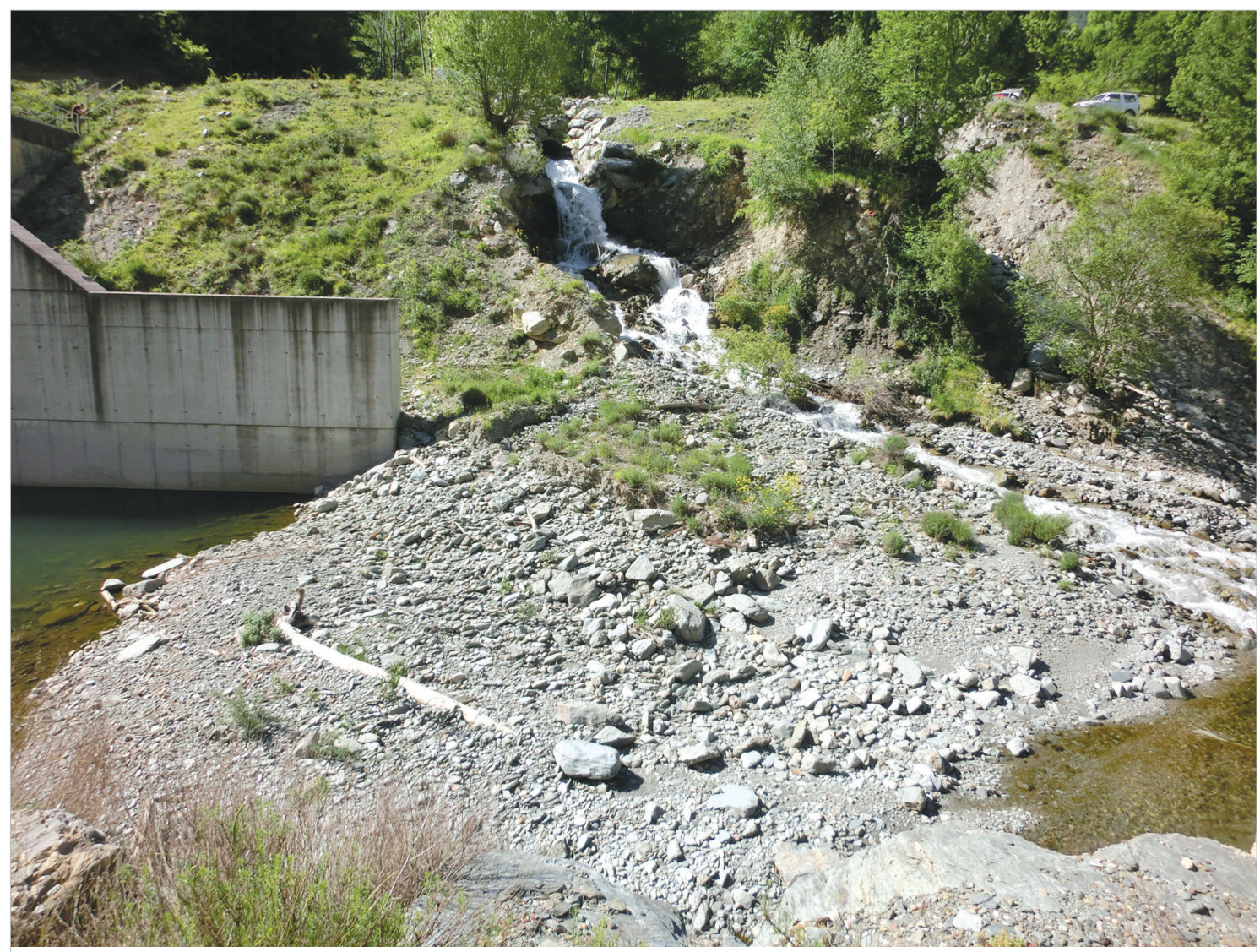

Fotografía 1. Desembocadura de los barrancos Portainé y Ramiosa en el río Romadriú o Santa Magdalena.

vias en cortos espacios de tiempo (Portilla et al., 2010; Luis Fonseca et al., 2011; Raïmat et al., 2013).

La zona de estudio se corresponde con la cabecera de la cuenca de Portainé, donde se localizan los torrentes de Portainé y de Reguerals (afluente del de Portainé), hasta su confluencia aguas abajo.

La problemática surge en los últimos años, por las desestabilizaciones del lecho y los márgenes de estos barrancos a raíz de la construcción de una estación de esquí de homónimo nombre, Port Ainè, inaugurada en 1986. Se han producido numerosos eventos de movilización de grandes volúmenes de materiales o "debrisflow", obstruyendo los accesos al complejo y llegando a producir daños en la central hidroeléctrica situada en la desembocadura de la cuenca (Raïmat et al., 2013). 


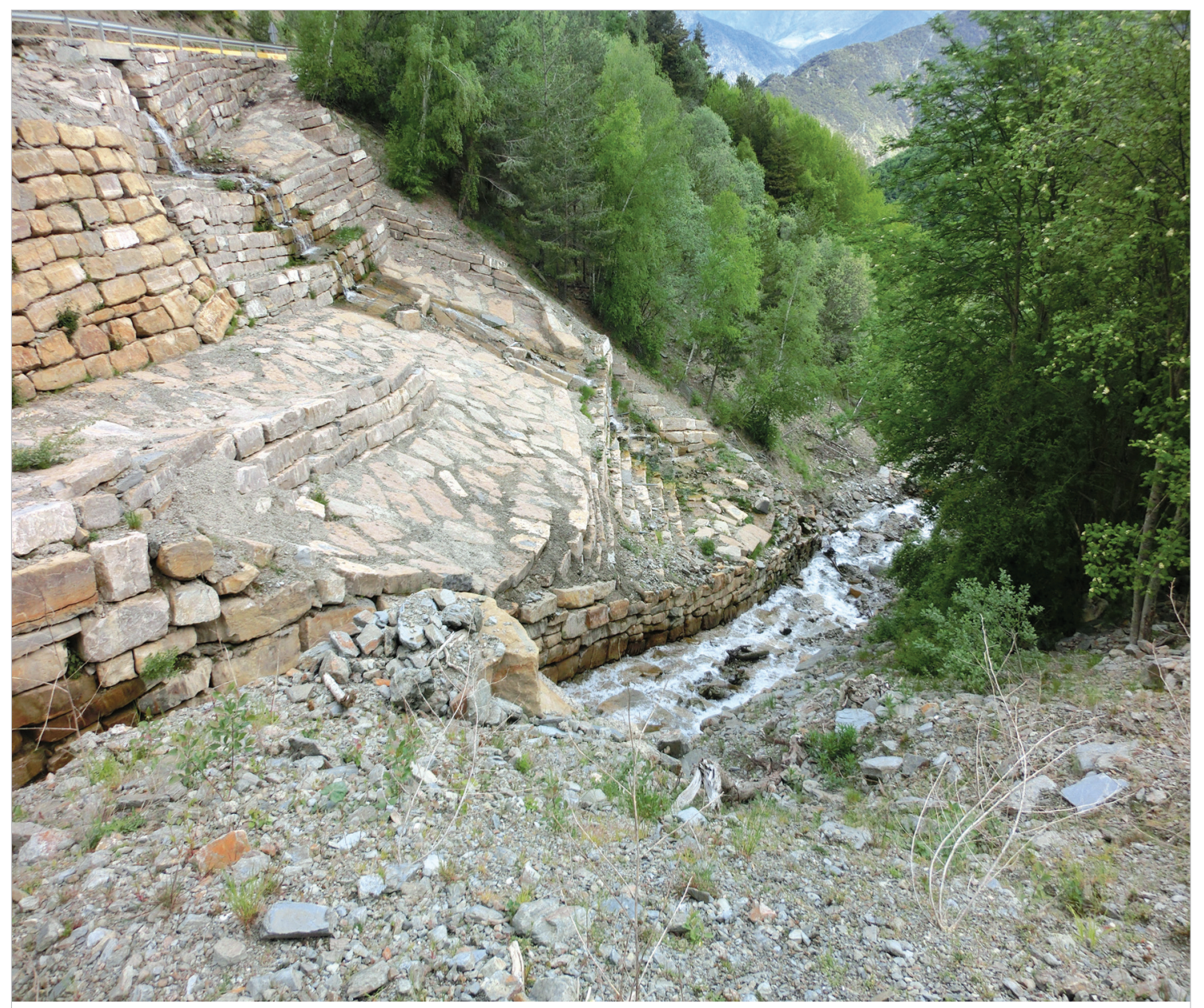

Fotografía 2. Barranco de Portainé atravesando la carretera de acceso a la estación de esquí. Se pueden ver las obras de reforzamiento de las laderas.

Se han dedicado numerosos recursos para intentar estabilizar, proteger y reparar los daños, con medidas como son las construcciones de escolleras, canales de drenaje para evacuar el agua, e instalación de protecciones tipo malla de retención de materiales y grandes bolos.

Pero no se ha resuelto el problema, y cada vez se necesitan de mayores actuaciones y recursos para la reparación de los desperfectos. Todos estos desperfectos ocurren con lluvias no necesariamente excepcionales.

Ante esta problemática, técnicos de diferentes organismos e instituciones analizan los riesgos en Portainé, que en los últimos tres años se nuclean en el proyecto CHARMA (ref: CGL2013-40828-R).

\subsection{Objetivos}

El objetivo principal de este trabajo es estudiar el efecto de los cambios de uso del suelo en la respuesta hidrológica del barranco de Portainé. 


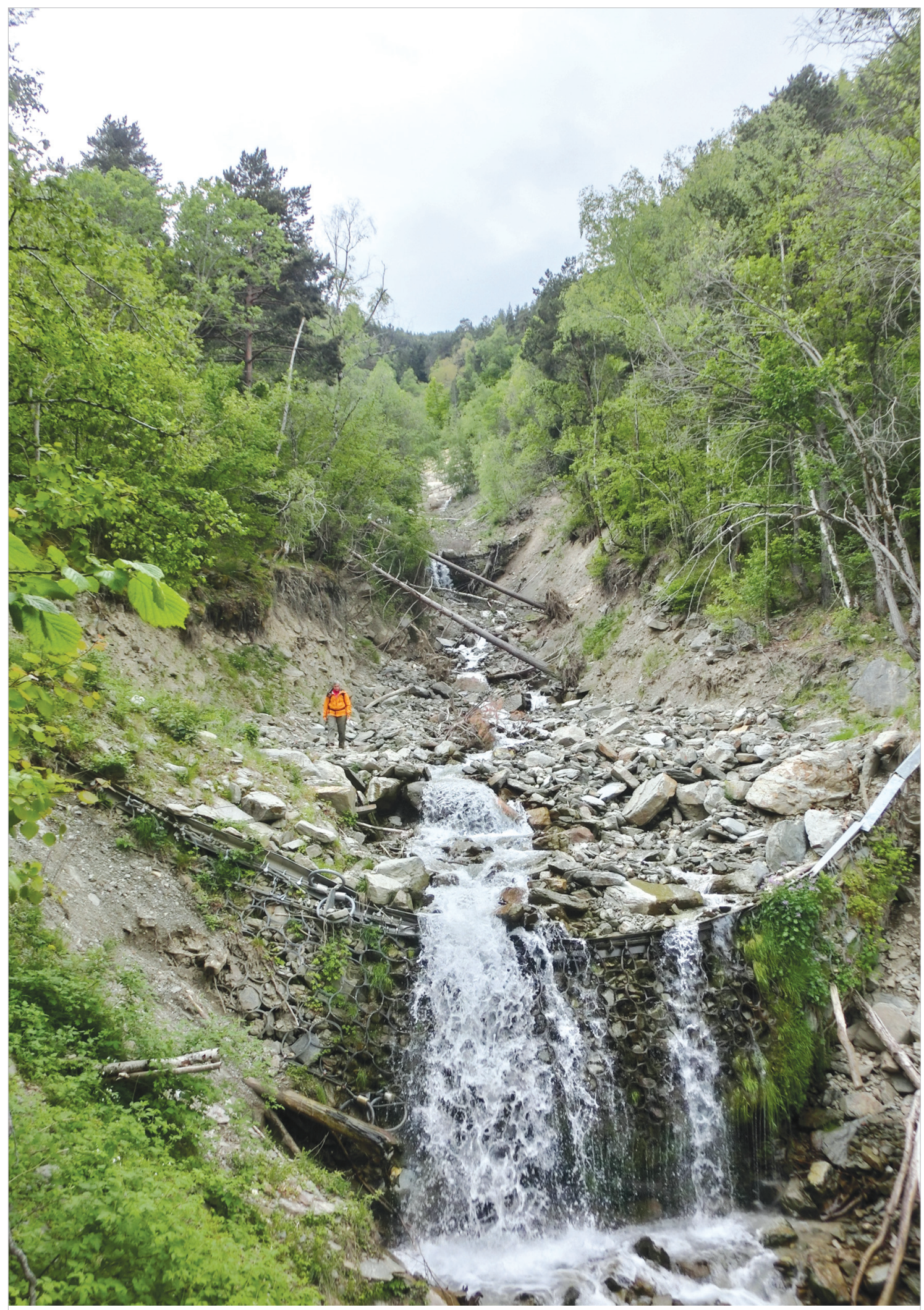

Fotografía 3. Barranco de Portainé con las mallas transversales de retención de materiales. 


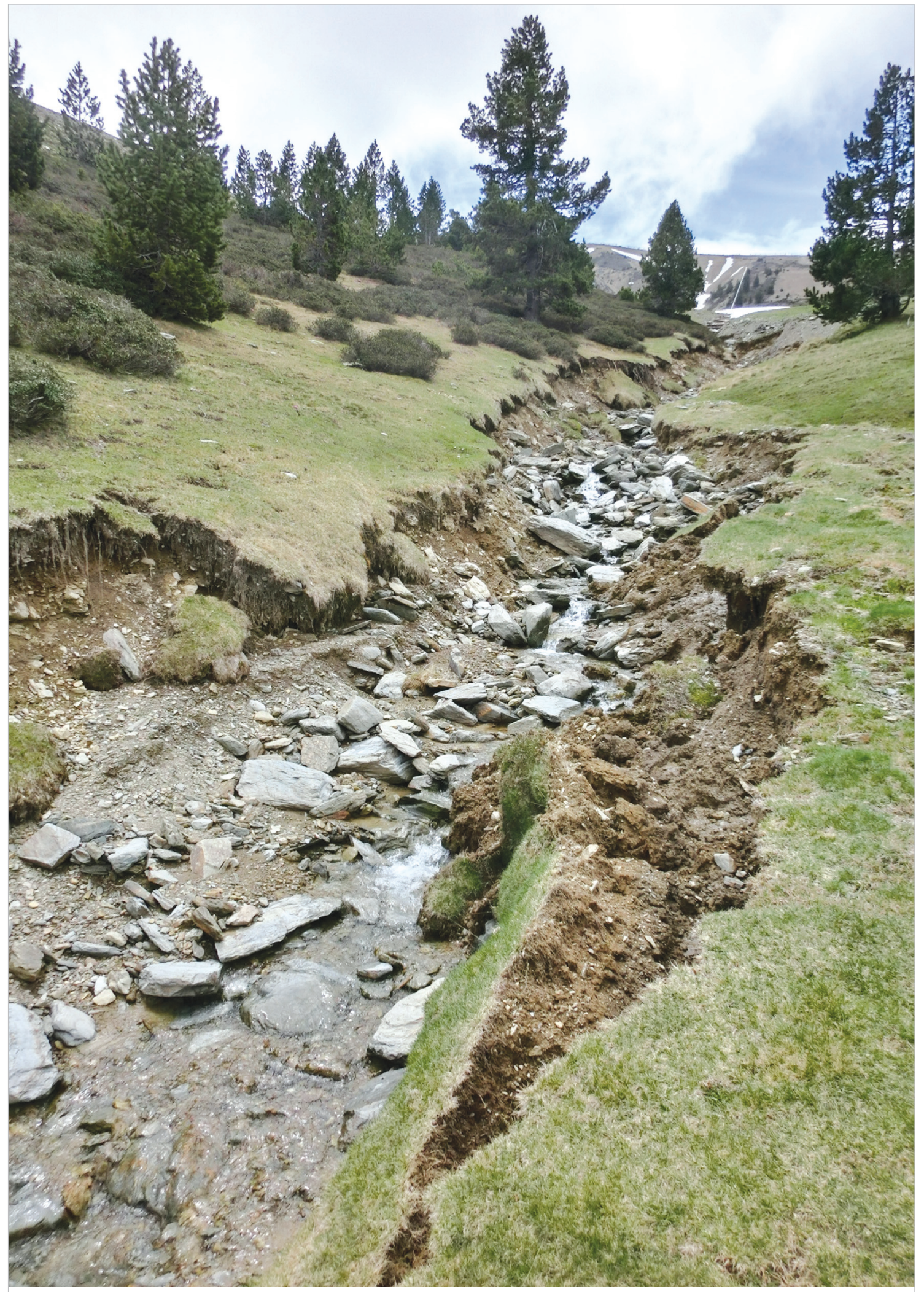

Fotografía 4. Cárcavas producidas en las pistas de esquí de la estación de Port Ainè. 
Y como objetivos secundarios se establecieron

- Estimar la variación de los números de curva $(\mathrm{CN})$ de diferentes años.

- Crear modelos de cuenca representativos para las diferentes situaciones.

- Estudio de las características morfométricas de la cuenca.

- Desarrollar modelos meteorológicos con diferentes hietogramas.

- Estimar los caudales punta de avenida para distintos años.

- Simular la respuesta hidrológica de la cuenca con diferentes hietogramas y periodos de retorno.

- Comparar resultados de la respuesta de caudales punta de los años 1956, 1996 y actual.

\section{Metodología}

De los diferentes tipos de métodos para el estudio de la respuesta hidrológica ante eventos de avenida (Díez-Herrero et al., 2008) se han escogido métodos hidrológicos de transformación precipitación-aportación. Mediante el esquema de la figura 2 se sintetiza la metodología utilizada.

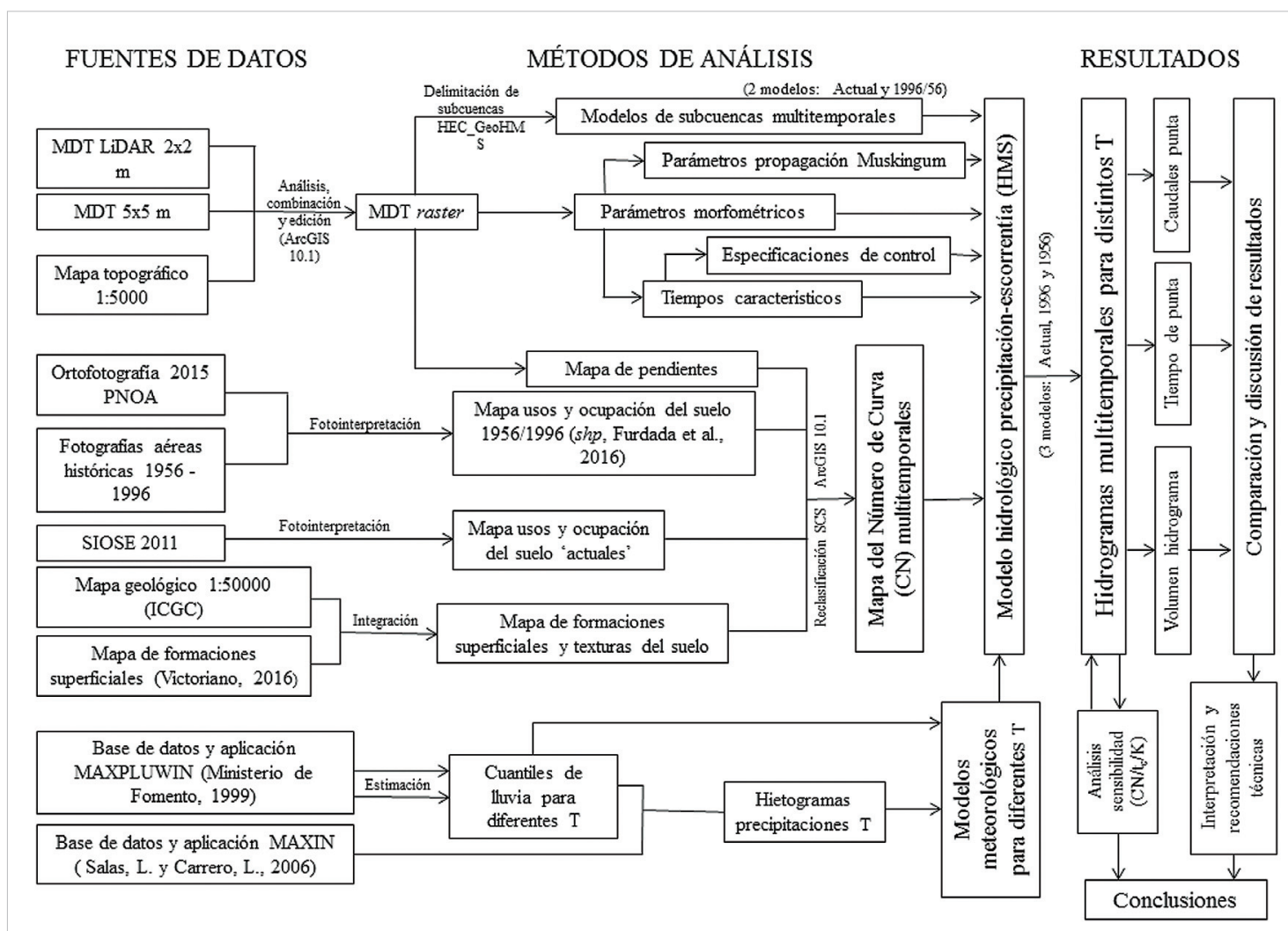

Figura 2. Esquema de la metodología seguida en los tratamientos de los datos y aplicación de las diferentes técnicas. 


\subsection{Fuentes de datos topográficos y temáticos}

Se recopiló información de diferentes bases de datos cartográficas institucionales, y suministrada por personas del equipo del proyecto CHARMA.

- Modelo digital del terreno (MDT) procedente de LiDAR 2x2 m, con fecha del 2011 del Instituto Cartográfico y Geológico de Cataluña (ICGC).

- MDT 5x5 m, con fecha del 2011 del Instituto Geográfico Nacional (IGN).

- Mapa topográfico 1:5000 del ICGC.

- Plan Nacional de Ortofotografía Aérea (PNOA) del IGN con fecha de 2015.

- Imágenes históricas del ICGC, para los años 1996 y 1956.

- Sistema de Información sobre Ocupación de Suelo de España (SIOSE) actual del IGN con fecha de 2011.

- Capas en formato shape (shp) de ArcGIS (ESRI Geosystems) con los usos del suelo de los años 1996 y 1956 (Furdada et al., 2016).

- Capas en formato shp de las diferentes formaciones superficiales en la cabecera de Portainé (Victoriano et al., 2016).

\subsection{Modelo de cuenca}

Se decidió generar dos MDT (ó DEM) a partir de herramientas SIG:

- MDT (2x2m) para el modelo de cuenca actual, generado a partir de un vuelo LiDAR con fecha de 2011.

- MDT $(5 \times 5 \mathrm{~m})$ para las situaciones pasadas 1956-1996, generado a partir de un mapa topográfico 1:5000 del ICGC, asegurándose de su pertenencia a situaciones anteriores a la actual.

Seguidamente, se procedió a la delineación de las cuencas y la red de drenaje (Bodoque, 2012) para posteriormente extraer sus parámetros morfométricos (máxima longitud de flujo, área de la cuenca, pendiente de los cauces), y tiempos característicos (tiempo de concentración o $t_{c} \mathrm{y}$ tiempo de retardo o $t_{\mathrm{lag}}$ ).

\subsection{Modelo de escorrentía}

Para poder calcular la precipitación neta $(\mathrm{Pn})$, o aquella precipitación que genera escorrentía, se utilizó en el método del "Número de Curva" (CN) del Servicio de Conservación de Suelos de los EE.UU (S.C.S) (NRCS, 2004a y 2007), el cuál esta implementado en el modelo HEC-HMS (HEC, 2015). Este método se basa en un número adimensional que varían entre 0 y 100 ; donde en una zona con un $\mathrm{CN}=0$ no hay escorrentía y todo lo que llueve se infiltra, y otra con $\mathrm{CN}=100$ es impermeable y toda la precipitación genera escorrentía, tomando en cuenta las condiciones de humedad antecedente del suelo (seco, intermedio y húmedo).

Para su cálculo se debe de obtener previamente el umbral de escorrentía $\left(\mathrm{P}_{0}\right)$ mediante el cruce de tres variables: 
- Los grupos hidrológicos del suelo.

- Los usos del suelo.

- Las pendientes de la zona.

Los grupos hidrológicos del suelo se obtuvieron a partir de la cartografía del ICGC, completado con el tipo de formaciones superficiales (Victoriano et al., 2016.

Los usos y ocupación del suelo se obtuvieron a partir del SIOSE y de la fotointerpretación de imágenes aéreas para las situaciones pasadas (Furdada et al., 2016), y las pendientes fueron extraídas a partir de los MDT generados en los modelos de cuenca.

A partir del cruce de estas tres variables se asignó un valor inicial de escorrentía $\left(\mathrm{P}_{0}\right)$ teniendo en cuenta las tablas de la Instrucción 5.2-IC (Ministerio de Fomento, 2016), y optando por una condición intermedia o tipo 2 de humedad antecedente del suelo.

Seguidamente se calcularon los $\mathrm{CN}$ para las diferentes situaciones y en cada subcuenca mediante su equivalencia $\mathrm{CN}-\mathrm{P}_{0}$ (Ferrer, 2003).

\subsection{Modelo meteorológico}

Para obtener los caudales de referencia en la salida de una cuenca, un dato básico son las precipitaciones máximas previsibles en un día con diferentes frecuencias.

Debido a la ausencia de estaciones meteorológicas con series de precipitaciones representativas de la zona, se optó por utilizar el software MAXIN (Salas, L. y Carrero, L., 2006) para obtener de manera fiable las máximas lluvias diarias asociadas a un periodo de retorno.

Se eligieron los periodos de retorno (T) de 10, 50, 100 y 500 años como objeto de estudio para la estimación de los cuantiles de lluvia, basándose en los mismos umbrales de peligrosidad del artículo 8 del Real Decreto 903/2010.

También se optó por incluir el T50 para realizar un análisis de sensibilidad de distintos valores, siendo éste intermedio entre el T10 y T100; dado que este periodo es muy frecuente en los estudios técnicos relacionados con los riesgos y la protección civil.

A continuación se calcularon las intensidades de precipitación a partir de las precipitaciones máximas diarias anuales (PMDA) para un intervalo de tiempo equivalente al tc basándose en la nueva formulación de Salas (2005), y Salas y Fernández (2006), y se crearon 3 hietogramas para cada T considerado $(10,100$ y 500; T50 se reservará para realizar un análisis de sensibilidad):

- Centrado.

- Sesgado al inicio del evento.

- Sesgado al final del evento para representar la variación de la intensidad de la precipitación a lo largo de $24 \mathrm{~h}$. 


\subsection{Modelo hidrológico}

\subsubsection{Hidrograma unitario}

Para la transformación de la lluvia neta en escorrentía se eligió el método del Hidrograma Unitario del SCS, y como flujo base, inexistente, ya que no hay ríos permanentes en la zona sino barrancos torrenciales muy dependientes de las lluvias y deshielos de las montañas.

Una vez obtenidos los hidrogramas que se generan en las cuencas, se puede proceder a determinar su circulación a través de los cauces. Para ello se decidió por la utilización del método de Muskingum, el cual modela el almacenamiento volumétrico del flujo en un cauce mediante la suma del almacenamiento en prisma y el almacenamiento en cuña (Chow et al., 1994).

Este método se basa en dos componentes principales dependientes de las características físicas de las zonas por donde circulan los hidrogramas: el parámetro $x \mathrm{y}$ el parámetro $K$, cuyos valores fueron calculados teniendo en cuenta la fórmula del National Weather Service (Fread, D. y Lewis, J. 1998), y de las características de los distintos tramos de circulación.

\subsection{Análisis de sensibilidad de parámetros hidrológicos}

Se realizó un análisis de sensibilidad con el objetivo de estudiar los parámetros que mayor influencia o error pudieran generar, y de los que más dependía el modelo para calcular los hidrogramas de salida como son: el número de curva, el tiempo de concentración y el valor $K$ de Muskingum. Para ello se reservó el periodo de retorno T50, y se calcularon los caudales punta en la desembocadura de la zona de estudio, comprobándose el rango de variación de resultados al valorar un aumento y una disminución del $10 \%$ en el valor de cada parámetro, y finalmente comprobándose que parámetro genera mayor variación en el modelo.

\section{Resultados}

\subsection{Resultados del modelo de cuenca}

En la figura 3, se presentan las subcuencas delimitadas para las diferentes situaciones: actual y 1996/56, a escala 1:18.000.

En las tablas 1 y 2 se muestran los parámetros morfométricos de cada subcuenca, de ambas situaciones (actual, 1996/56).

Los resultados de cada modelo permiten verificar la gran influencia que ejerce la construcción de la balsa central, la cual, condiciona la forma y distribución de las subcuencas. Por ejemplo, en el modelo de cuenca de 1996/56, la subcuenca 221 desaparece, y las de alrededor ocupan su espacio, debido a los cambios del drenaje superficial inducido por las pistas de esquí. 


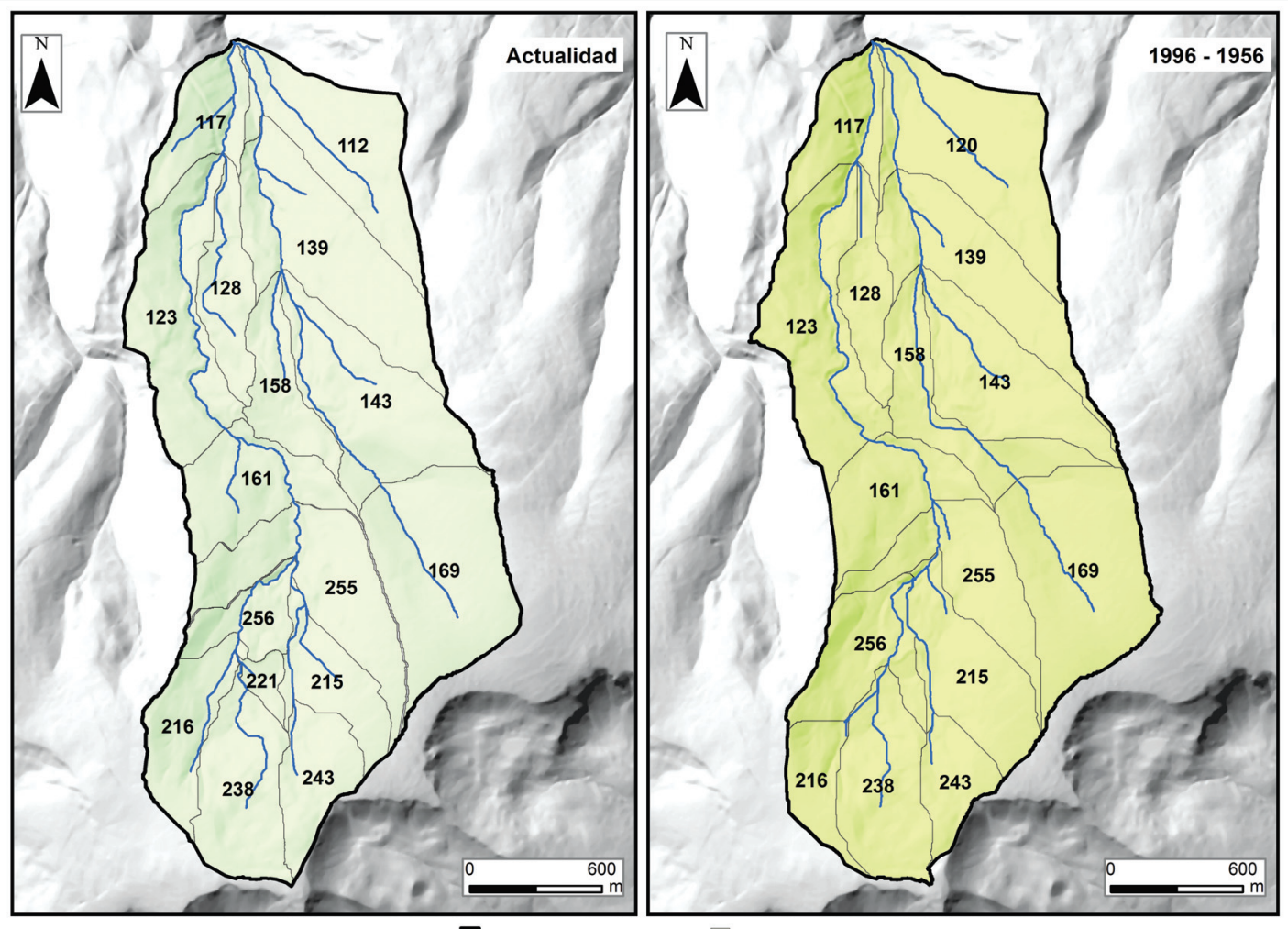

Leyenda: - Red de drenaje 5 Límite de cuenca 5 Subcuencas nnn Número de subcuenca

Figura 3. Modelos de cuenca de la cabecera de Portainé, para las situaciones actual y 1996/1956.

Tabla 1. Parámetros morfométricos y tiempos característicos del modelo de cuenca actual.

\begin{tabular}{|c|c|c|c|c|c|c|}
\hline & \multicolumn{2}{|c|}{ Subcuenca } & \multicolumn{2}{|c|}{ Cauce más largo } & \multirow[b]{2}{*}{$\mathrm{t}_{\mathrm{c}}(\mathrm{min})$} & \multirow[b]{2}{*}{$\mathrm{t}_{\text {lag }}\left(0.6^{*} \mathrm{t}_{\mathrm{c}}\right.$} \\
\hline & Nombre & Área $\left(\mathrm{km}^{2}\right)$ & Longitud (km) & Pendiente $\left(\mathrm{m}^{*} \mathrm{~m}^{-1}\right)$ & & \\
\hline \multirow{16}{*}{ 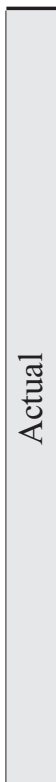 } & 112 & 0.28 & 1.57 & 0.45 & 29.50 & 17.70 \\
\hline & 117 & 0.17 & 1.02 & 0.39 & 21.81 & 13.09 \\
\hline & 123 & 0.39 & 1.85 & 0.32 & 35.60 & 21.36 \\
\hline & 128 & 0.18 & 1.39 & 0.38 & 27.88 & 16.73 \\
\hline & 139 & 0.48 & 2.14 & 0.38 & 38.54 & 23.12 \\
\hline & 143 & 0.42 & 1.70 & 0.28 & 34.30 & 20.58 \\
\hline & 158 & 0.18 & 1.22 & 0.30 & 26.20 & 15.72 \\
\hline & 161 & 0.27 & 1.14 & 0.22 & 26.66 & 16.00 \\
\hline & 169 & 0.50 & 1.23 & 0.21 & 28.53 & 17.12 \\
\hline & 215 & 0.19 & 1.31 & 0.23 & 29.17 & 17.50 \\
\hline & 216 & 0.20 & 1.20 & 0.23 & 27.41 & 16.45 \\
\hline & 221 & 0.04 & 0.51 & 0.20 & 14.71 & 8.83 \\
\hline & 238 & 0.27 & 1.33 & 0.20 & 30.33 & 18.20 \\
\hline & 243 & 0.17 & 0.86 & 0.27 & 20.55 & 12.33 \\
\hline & 255 & 0.37 & 1.32 & 0.24 & 29.11 & 17.47 \\
\hline & 256 & 0.12 & 0.84 & 0.20 & 21.32 & 12.79 \\
\hline T. & & 4.24 & & & & \\
\hline
\end{tabular}


Tabla 2. Parámetros morfométricos y tiempos característicos del modelo de cuenca 1996/56.

\begin{tabular}{|c|c|c|c|c|c|c|}
\hline & \multicolumn{2}{|c|}{ Subcuenca } & \multicolumn{2}{|c|}{ Cauce más largo } & \multirow[b]{2}{*}{$t_{c}(\min )$} & \multirow[b]{2}{*}{$t_{\text {lag }}\left(0.6 * t_{c}\right)$} \\
\hline & Nombre & Área $\left(\mathrm{km}^{2}\right)$ & Longitud (km) & Pendiente $\left(\mathrm{m}^{*} \mathrm{~m}^{-1}\right)$ & & \\
\hline \multirow{15}{*}{$\begin{array}{l}\stackrel{0}{2} \\
\stackrel{2}{\sigma} \\
2 \\
2\end{array}$} & 112 & 0.37 & 1.58 & 0.45 & 29.66 & 17.79 \\
\hline & 117 & 0.18 & 0.98 & 0.40 & 20.98 & 12.59 \\
\hline & 123 & 0.44 & 1.85 & 0.32 & 35.64 & 21.39 \\
\hline & 128 & 0.15 & 1.23 & 0.42 & 24.84 & 14.90 \\
\hline & 139 & 0.36 & 1.73 & 0.41 & 32.23 & 19.34 \\
\hline & 143 & 0.35 & 1.47 & 0.34 & 29.66 & 17.80 \\
\hline & 158 & 0.26 & 1.74 & 0.28 & 34.83 & 20.90 \\
\hline & 161 & 0.25 & 1.00 & 0.21 & 24.20 & 14.52 \\
\hline & 169 & 0.51 & 1.29 & 0.20 & 29.72 & 17.83 \\
\hline & 215 & 0.30 & 1.39 & 0.23 & 30.63 & 18.38 \\
\hline & 216 & 0.13 & 0.89 & 0.24 & 21.63 & 12.98 \\
\hline & 238 & 0.31 & 1.17 & 0.24 & 26.71 & 16.03 \\
\hline & 243 & 0.13 & 0.74 & 0.27 & 18.29 & 10.97 \\
\hline & 255 & 0.29 & 1.19 & 0.26 & 26.49 & 15.89 \\
\hline & 256 & 0.24 & 1.07 & 0.22 & 25.27 & 15.16 \\
\hline T. & & 4.25 & & & & \\
\hline
\end{tabular}

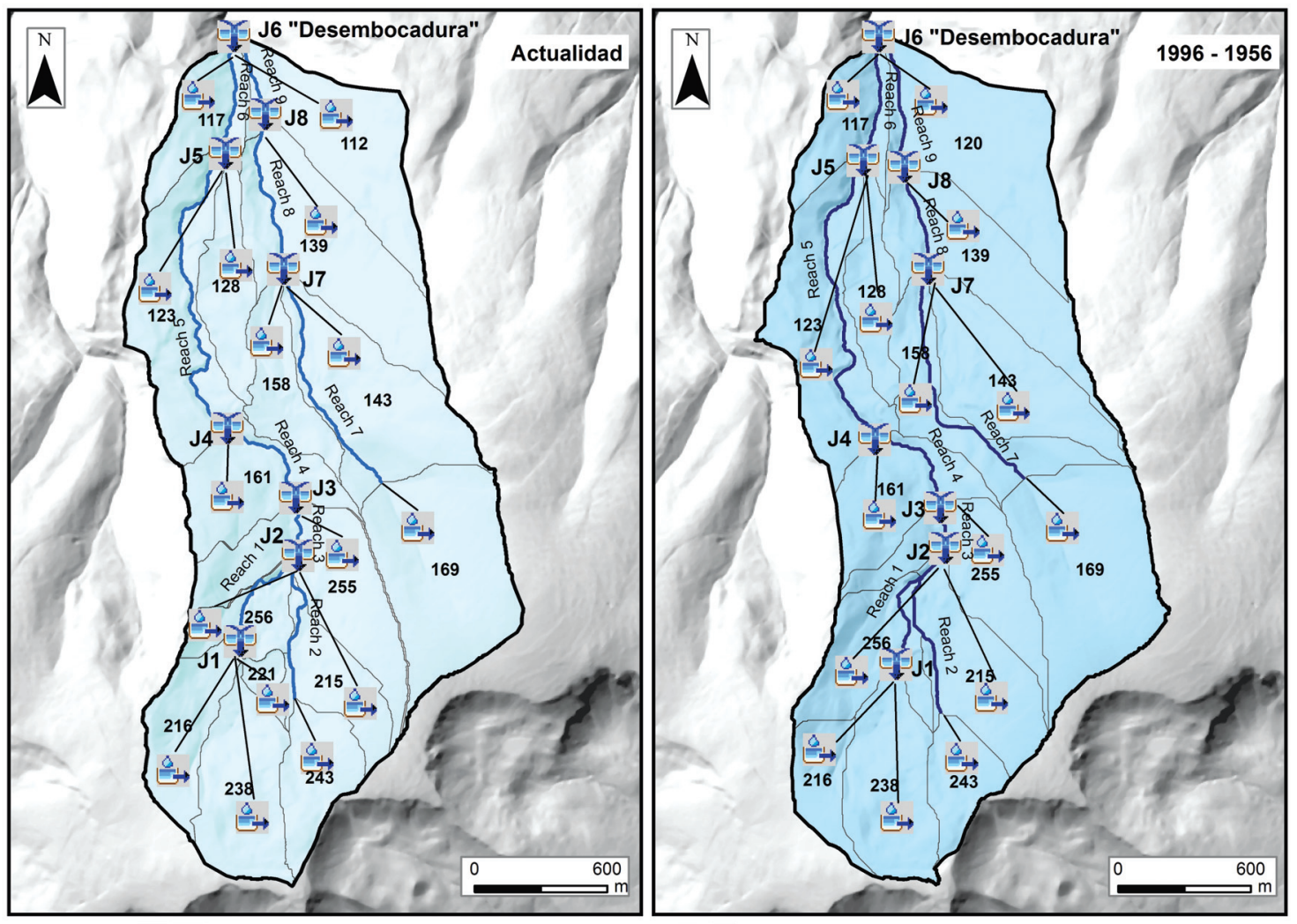

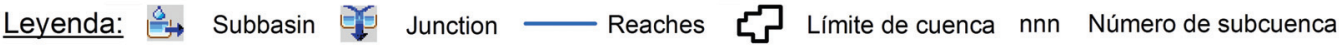

Figura 4. Modelos de cuenca de la cabecera de Portainé, para las situaciones actual y 1996/1956. 
A)

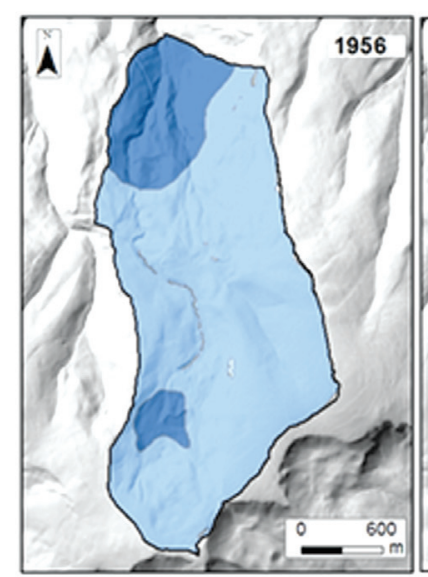

B)

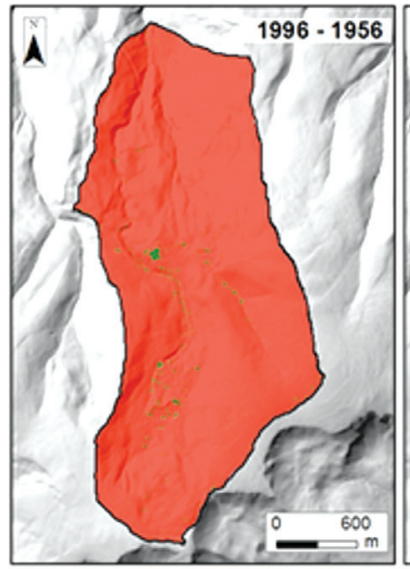

C)

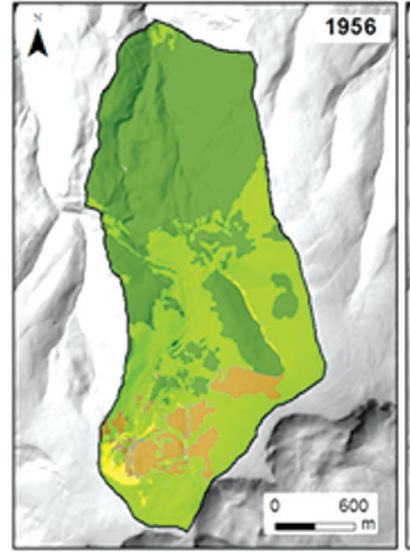

Lesenda:

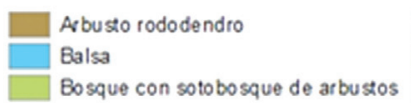

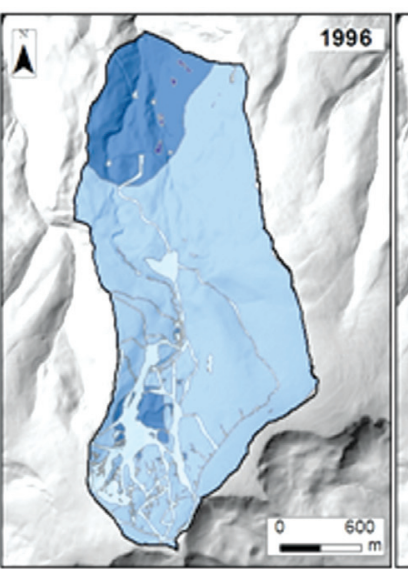

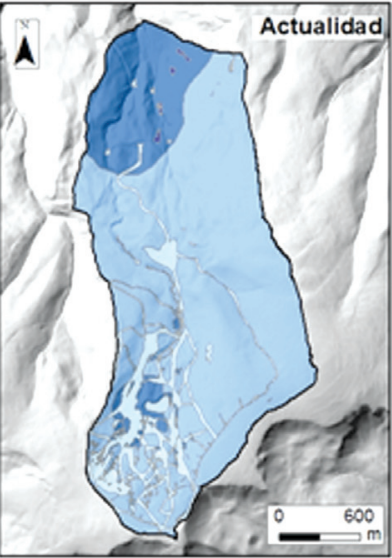

Leyenda:

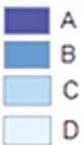

Limite
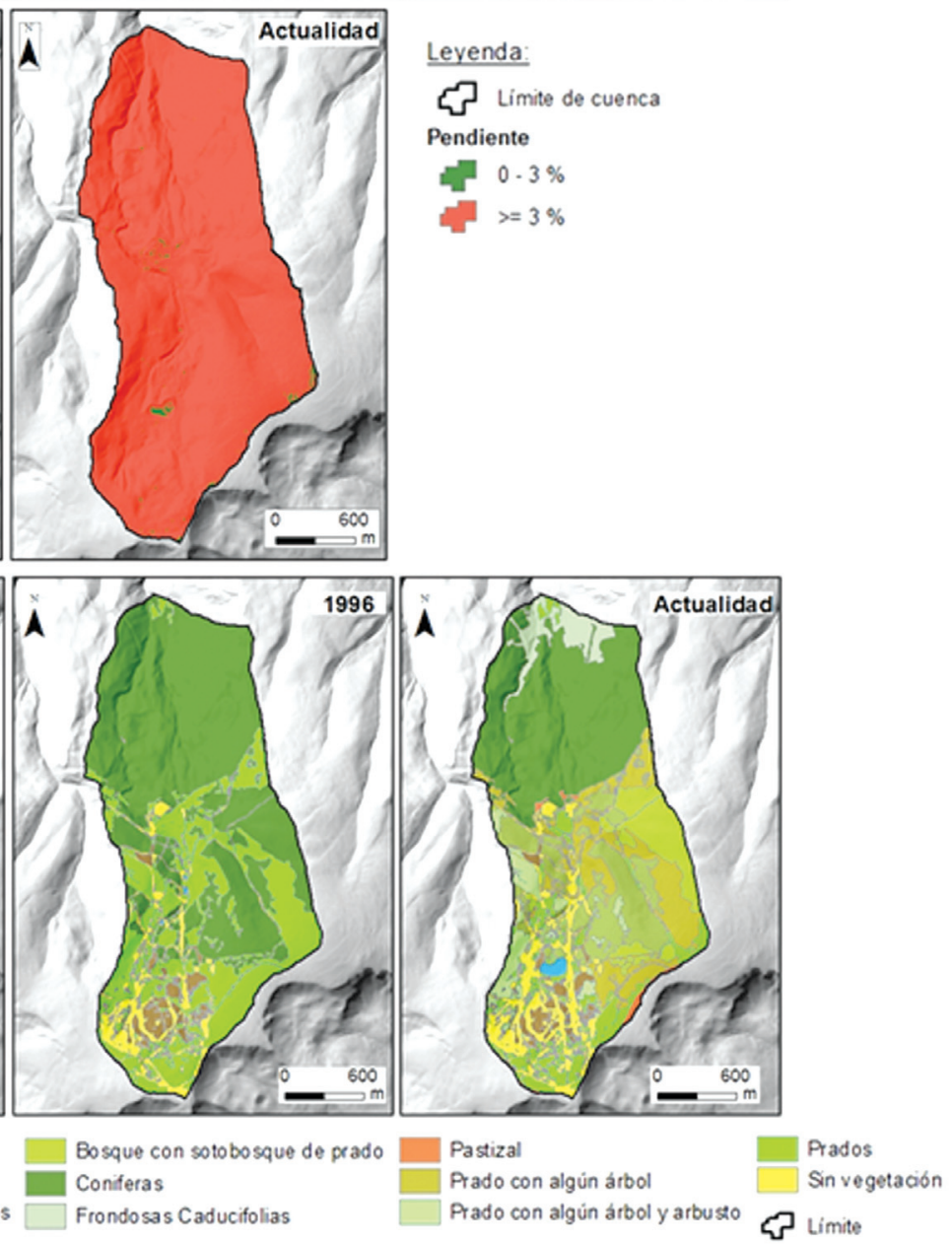

Figura 5. A) Evolución de los grupos hidrológicos del suelo de la cabecera de Portainé en las situaciones actuales, 1996 y 1956. B) Pendientes clasificadas de la cabecera de Portainé para los modelos de cuenca actual y 1996-1956. C) Evolución de la ocupación y usos del suelo desde 1956 hasta la actualidad. Gráfico de porcentaje y tipo de suelo ocupado en cada uno de los años. Fuente: SIOSE e información de fotointerpretación proporcionada por Gloria Furdada (Furdada et al., 2016). 
También se observa diferencia en el recorrido del cauce más largo, que es más corto en el modelo de 1996/56 que en el actual, debido igualmente, a la ausencia de la balsa.

En términos generales, los cambios no son muy significativos entre los modelos actual y 1996/56, exceptuando lo mencionado sobre la balsa; pero sí que se tienen que tener en cuenta ya que en esta zona es donde se han producido los cambios antrópicos más significativos.

Con estos resultados anteriores, se crearon esquemas de modelos de cuencas para ambas situaciones, en el programa HEC-HMS 4.0 (Figura 4).

\subsection{Resultados del modelo de escorrentía}

Mediante SIG se generó un grid para cada variable necesaria, para generar el CN. En la figura 5 se observa el resultado de cada variable.

Obteniéndose los diferentes grupos hidrológicos de la cabecera de Portainé, como se observa en la figura $5 \mathrm{~A}$, puede apreciarse que las modificaciones de las formaciones superficiales no son significativas, salvo en la cabecera de la cuenca, donde los movimientos del terreno antrópicos asociados a la instalación de la estación de esquí y sus accesos, sí que modifican amplias superficies.

Después, se clasificaron las pendientes en 2 grupos: pendientes hasta el 3\%, y pendientes mayores o iguales al 3\% (Figura 5B).

Se observa que al estar situada la zona en los Pirineos, la gran mayoría de las pendientes son mayores al 3\%, característica importante a la hora de cruzar las variables para obtener el número de curva.

Por último se obtuvieron los mapas de ocupación y usos del suelo (Figura 5C), en la que se observa principalmente una disminución en la cubierta de arbusto rododendro desde 1956 hasta la actualidad y un aumento del porcentaje de terreno sin vegetación, todo esto a raíz del desarrollo de actividades antrópicas en la zona, como es la estación de esquí de Portainé.

Con todas estas variables, y mediante las herramientas proporcionadas por la extensión Geo-HMS de ArcGis 10.1, se han cruzado todas las variables obteniéndose una cobertura raster de $5 \times 5 \mathrm{~m}$ del número de curva en la cabecera de la cuenca, y para cada situación estudiada (Figura 6).

Como resultado se observa el aumento del $\mathrm{CN}$ en el sector de cabecera, donde se ha producido la construcción y ampliación de las pistas de esquí, las cuáles favorecen la escorrentía en toda esta zona. Estos resultados del CN por subcuencas vienen mostrados en la tabla 3.

Se observan las mayores diferencias en las cuencas 238, 243 y 256, con aumentos del 11, 9, y 12\% respectivamente, correspondientes a las zonas donde se ha ampliado significativamente la superficie de pistas de esquí.

\subsection{Resultados del modelo de meteorológico}

Para la estimación de los cuantiles de lluvia se eligió el punto, perteneciente al 

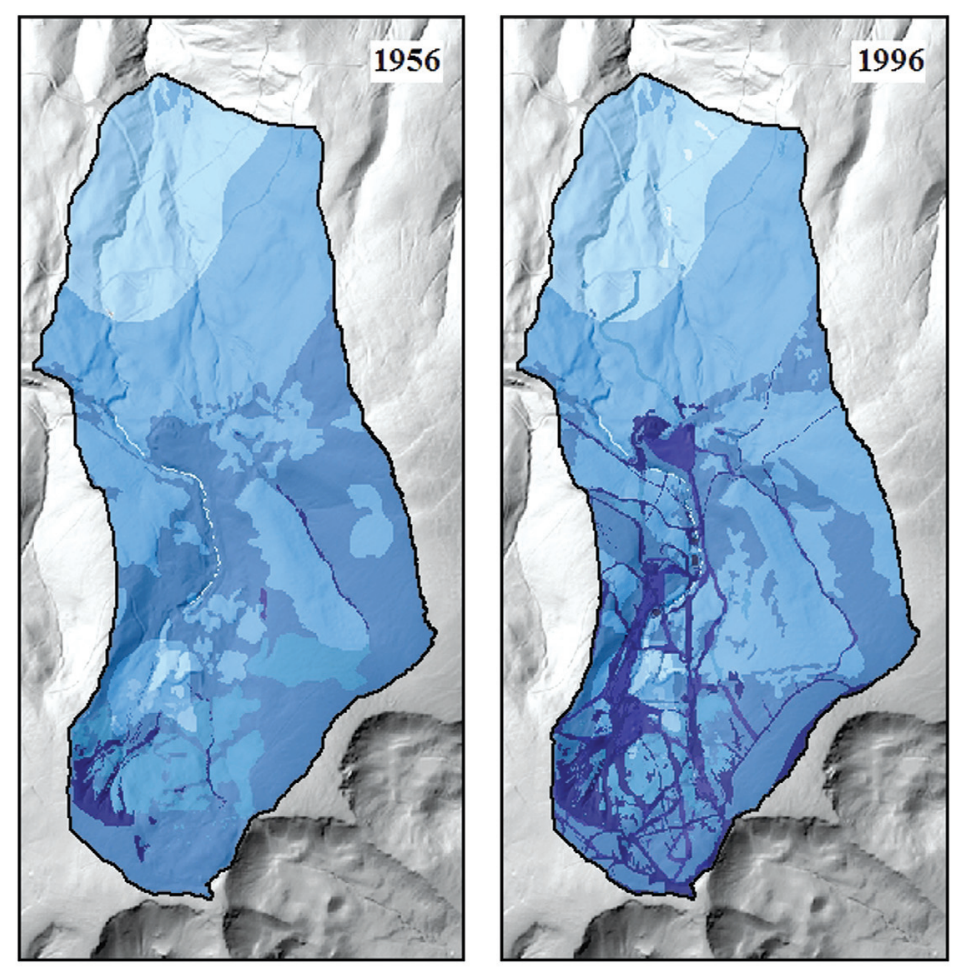

Leyenda

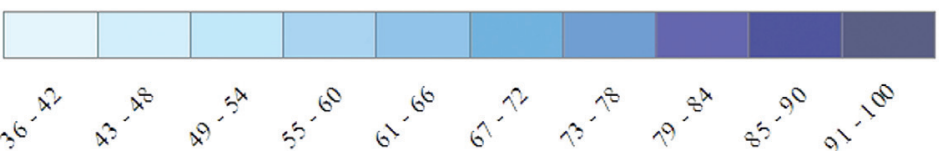

Figura 6. Evolución del Número de Curva en la cabecera de Portainé, en la situación actual, 1996 y 1956. Capas en formato raster de $5 \times 5 \mathrm{~m}$.

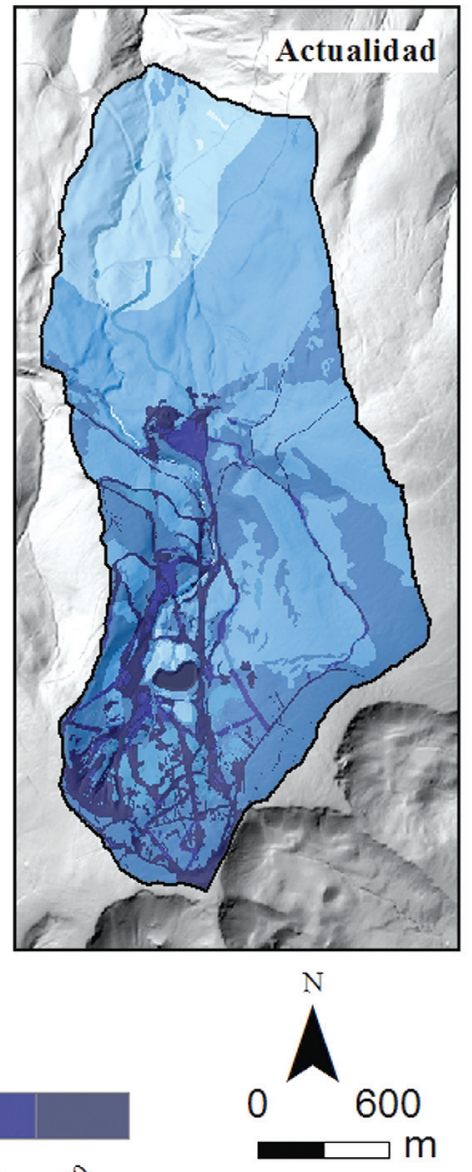


Tabla 3. Umbrales de escorrentía $\left(\mathrm{P}_{0}\right)$ y Números de curva $(\mathrm{CN})$ de cada subcuenca en las distintas situaciones estudiadas, y sus porcentajes de cambio entre 1956 y la actualidad.

\begin{tabular}{|c|c|c|c|c|c|c|c|}
\cline { 2 - 7 } \multicolumn{1}{c|}{} & \multicolumn{2}{c}{ Actualidad } & \multicolumn{2}{c|}{1996} & \multicolumn{2}{c|}{1956} & \multicolumn{1}{c|}{ \% Cambio (Actual-1956) } \\
\hline Subcuenca & $\mathrm{P}_{0}$ & $\mathrm{CN}$ & $\mathrm{P}_{0}$ & $\mathrm{CN}$ & $\mathrm{P}_{0}$ & $\mathrm{CN}$ & \% \\
\hline 112 & 37 & 58 & 38 & 57 & 37 & 58 & 0 \\
117 & 46 & 52 & 47 & 52 & 47 & 52 & 0 \\
123 & 34 & 60 & 32 & 61 & 34 & 60 & 1 \\
128 & 36 & 59 & 35 & 59 & 37 & 58 & -1 \\
139 & 34 & 60 & 32 & 61 & 32 & 61 & -3 \\
143 & 28 & 65 & 29 & 64 & 25 & 67 & 4 \\
158 & 21 & 71 & 24 & 68 & 24 & 68 & 7 \\
161 & 19 & 73 & 20 & 72 & 24 & 68 & -3 \\
169 & 24 & 68 & 24 & 68 & 22 & 70 & 5 \\
215 & 17 & 75 & 18 & 74 & 21 & 71 & 4 \\
216 & 11 & 82 & 10 & 84 & 14 & 79 & - \\
221 & 11 & 82 & - & - & - & - & 11 \\
238 & 11 & 82 & 14 & 79 & 19 & 73 & 9 \\
243 & 13 & 80 & 14 & 78 & 19 & 73 & 0 \\
255 & 21 & 71 & 22 & 70 & 21 & 71 & 12 \\
256 & 17 & 75 & 18 & 74 & 26 & 66 & \\
\hline
\end{tabular}

Tabla 4. Resultados de PMDA obtenidos con MAXIN 2.0 para el punto más cercano a la cuenca de Portainé, situado en el término municipal de Sort.

\begin{tabular}{|c|c|c|c|c|}
\cline { 2 - 5 } \multicolumn{1}{c|}{} & \multicolumn{3}{c|}{} & Zonas h $(\mathrm{T})$ \\
\cline { 2 - 4 } \multicolumn{1}{c|}{} & Datos & h cortas & h largas & $\mathrm{F}$ \\
\hline PMDA & 59 & 1 & 2 & 0.13 \\
\hline $\mathrm{K}$ & 6 & \multicolumn{3}{c}{} \\
\hline $\mathrm{a}$ & 0.175 & & & \\
\hline $\mathrm{Cv}$ & 0.37 & \multicolumn{3}{c}{} \\
\hline
\end{tabular}

\begin{tabular}{|c|c|c|c|c|c|c|c|c|}
\cline { 2 - 9 } \multicolumn{1}{c|}{} & \multicolumn{8}{c|}{ Periodo de retorno } \\
\cline { 2 - 9 } \multicolumn{1}{c|}{} & 2 años & 5 años & 10 años & 25 años & 50 años & 100 años & 200 años & 500 años \\
\hline PMDA (T) & 54.10 & 72.69 & 86.20 & 104.90 & 119.30 & 134.58 & 151.69 & 174.23 \\
\hline PM24 (T) & 61.13 & 82.14 & 97.41 & 118.54 & 134.81 & 152.08 & 171.41 & 196.88 \\
\hline
\end{tabular}

Valores de PMDA (T) y PM24 (T) en mm

A) Los hietogramas sesgados a la derecha, producen hidrogramas con caudales demasiado grandes debido a que el suelo está saturado, con baja capacidad de infiltración.

B) Los segados a la izquierda, producen hidrogramas con volúmenes reducidos debido a la alta capacidad de drenaje del suelo, antes de saturarse. 
Tabla 5. Resultados de la utilización de los diferentes hietogramas en los puntos de control J6 y J3, para el modelo de cuenca actual. Dónde: $\mathrm{Q}_{\mathrm{p}}=$ Caudal punta; $\Delta$ de $\mathrm{Q}_{\mathrm{p}}=$ diferencia de caudales punta en porcentaje.

\begin{tabular}{|c|c|c|c|}
\hline \multicolumn{4}{|c|}{ Hidrogramas "Cambios significativos en usos del suelo" (Junction 3) } \\
\hline $\mathrm{T}$ & Modelo hietograma & $\mathrm{Q}_{\mathrm{p}}\left(\mathrm{m}^{3} \mathrm{~s}^{-1}\right)$ & $\Delta$ de $\mathrm{Q}_{\mathrm{p}}(\%)$ \\
\hline \multirow{3}{*}{10} & Sesgado izquierda & 2.2 & 48 \\
\hline & Centrado & 4.6 & 100 \\
\hline & Sesgado derecha & 6.3 & 136 \\
\hline \multirow{3}{*}{100} & Sesgado izquierda & 6.2 & 62 \\
\hline & Centrado & 10 & 100 \\
\hline & Sesgado derecha & 12 & 120 \\
\hline \multirow{3}{*}{500} & Sesgado izquierda & 10.3 & 70 \\
\hline & Centrado & 14.7 & 100 \\
\hline & Sesgado derecha & 16.9 & 115 \\
\hline
\end{tabular}

\begin{tabular}{|c|c|c|c|}
\hline \multicolumn{4}{|c|}{ Hidrogramas "Desembocadura" (Junction 6) } \\
\hline $\mathrm{T}$ & Modelo hietograma & $\mathrm{Q}_{\mathrm{p}}\left(\mathrm{m}^{3} \mathrm{~s}^{-1}\right)$ & $\Delta$ de $\mathrm{Q}_{\mathrm{p}}(\%)$ \\
\hline
\end{tabular}

\begin{tabular}{|c|c|c|c|}
\hline \multirow{3}{*}{10} & Sesgado izquierda & 2.8 & 35 \\
\cline { 2 - 4 } & Centrado & 8.1 & 100 \\
\cline { 2 - 4 } & Sesgado derecha & 12.8 & 158 \\
\hline
\end{tabular}

\begin{tabular}{|c|c|c|c|}
\hline \multirow{3}{*}{100} & Sesgado izquierda & 10.2 & 50 \\
\cline { 2 - 4 } & Centrado & 20,5 & 100 \\
\cline { 2 - 4 } & Sesgado derecha & 27,4 & 134 \\
\hline
\end{tabular}

\begin{tabular}{|c|c|c|c|}
\hline \multirow{3}{*}{500} & Sesgado izquierda & 18.7 & 58 \\
\cline { 2 - 4 } & Centrado & 32.4 & 100 \\
\cline { 2 - 4 } & Sesgado derecha & 40.4 & 125 \\
\hline
\end{tabular}

\subsubsection{Resultados del análisis de sensibilidad de parámetros hidrológicos}

La tabla 6 recoge los porcentajes resultantes de los diferentes cálculos variando los parámetros analizados para ver su sensibilidad en los resultados.

Se observa que el $\mathrm{CN}$ es mucho más sensible que el resto de variables consideradas. Tiene un cambio del $48 \%$ entre el valor aumentado y reducido un $10 \%$; mientras que la siguiente variable más sensible, es el tc con una variación del 3\%, muy alejada del cambio producido en el $\mathrm{CN}$.

Esto significa que pequeñas variaciones en el $\mathrm{CN}$, producen mayores cambios en los caudales punta que las variaciones en el resto de variables. 
Tabla 6. Resultados del análisis de sensibilidad de las variables CN, tc, y K de Muskingum.

\begin{tabular}{|c|c|c|c|}
\hline \multicolumn{4}{|c|}{ Análisis de sensibilidad, T50 Centrado Junction 6, "Desembocadura" } \\
\hline Variable & Modelo hietograma & $\mathrm{Qp}\left(\mathrm{m}^{3} \mathrm{~s}^{-1}\right)$ Desembocadura & $\%$ Cambio \\
\hline \multirow{3}{*}{$\mathrm{CN}$} & $\mathrm{CN}-10 \%$ & 11.3 & \multirow{3}{*}{48} \\
\hline & Centrado & 16 & \\
\hline & $\mathrm{CN}+10 \%$ & 21.8 & \\
\hline \multirow{3}{*}{$t_{c}$} & $\mathrm{t}_{\mathrm{c}}-10 \%$ & 16.7 & \multirow{3}{*}{3} \\
\hline & Centrado & 16.4 & \\
\hline & $t_{c}+10 \%$ & 16.2 & \\
\hline \multirow{3}{*}{$K$} & $\mathrm{~K}-10 \%$ & 16.6 & \multirow{3}{*}{2} \\
\hline & Centrado & 16.4 & \\
\hline & $\mathrm{K}+10 \%$ & 16.3 & \\
\hline
\end{tabular}

A la vista de este resultado, se revisó con mucho detalle el procedimiento de asignación de número de curva a cada uno de los usos de suelo. No se apreciaron errores respecto a los criterios formulados, aunque sí persisten incertidumbres inherentes al propio método y a las fuentes de información.

\subsubsection{Variaciones en los caudales entre diferentes situaciones temporales}

Para realizar la modelización hidrológica, se consideraron los siguientes puntos de control (Figura 7):

- Junction 3: cabecera de Portainé donde se han producido cambios significativos en los usos del suelo.

- Junction 5: en Portainé, justo antes de la unión con Regerals.

- Junction 8: en Regerals, punto equivalente al Junction 5.

- Junction 7: en Regerals.

- Junction 6: Unión de Portainé con Regerals.

Los resultados hidrológicos se muestran en la tabla 7 , donde se reflejan los Qp, el volumen del hidrograma, y el porcentaje de cambio entre la situación de 1956 y la actual; para los distintos periodos de retorno y las distintas situaciones.

\section{Discusión}

\subsection{Discusión de los resultados obtenidos}

Como se ha podido observar en los resultados de las simulaciones, los cambios que se producen entre la situación de 1956, y la situación actual, son mucho más pronunciados en el barranco de Portainé que en Regerals. Fundamentalmente debido a que los cambios producidos, en las instalaciones de la estación de esquí, han 


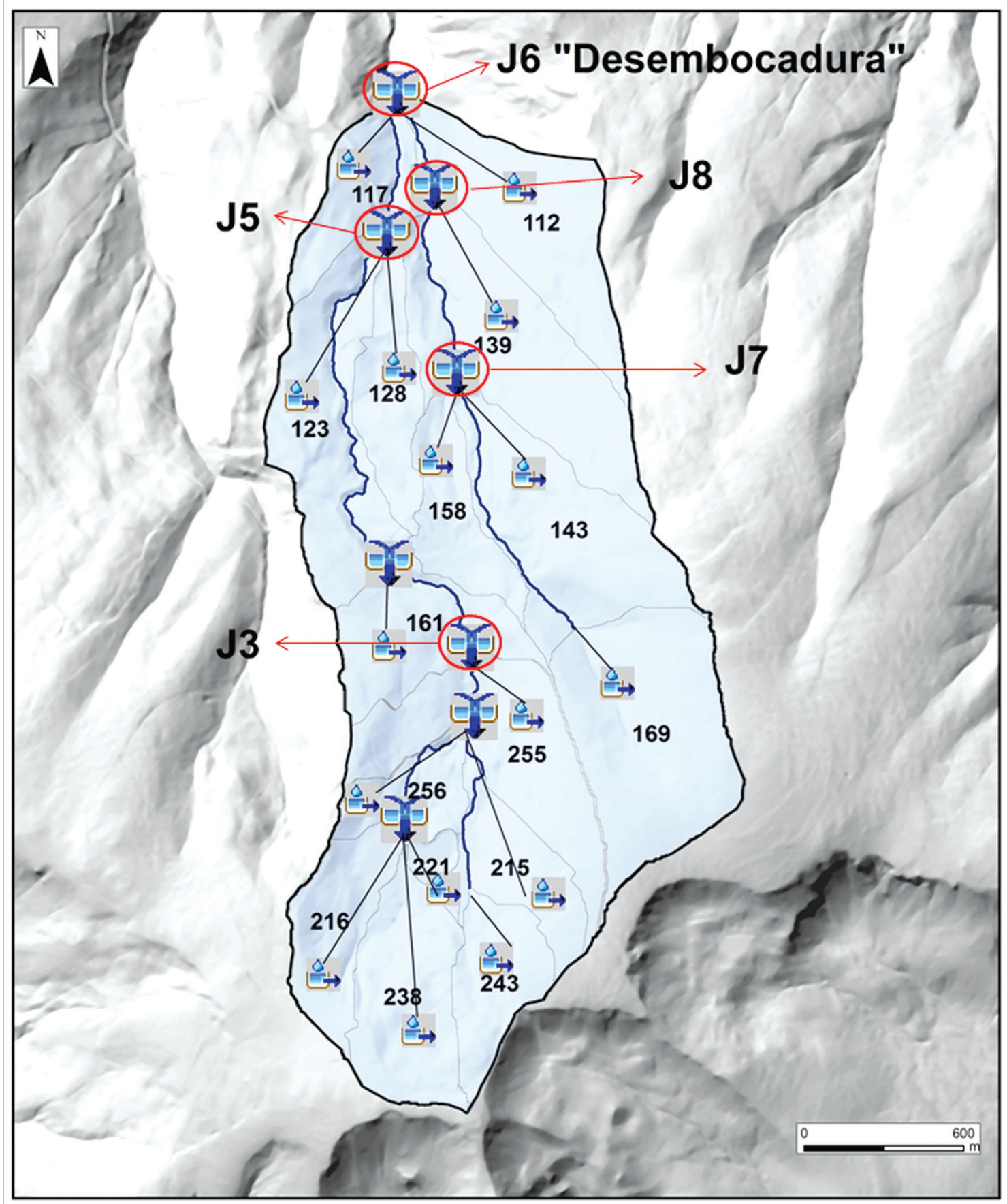

Figura 7. Localización de los puntos de control utilizados en los modelos.

sido mayores en Portainé, como se ve en la evolución de la ocupación del suelo de la figura 10.

Hay diferencias significativas en los Qp en la desembocadura, las cuáles van disminuyendo con periodos de retorno mayores (Tabla 8). 
Tabla 7. Resultados comparados entre las distintas situaciones estudiadas en los puntos de control seleccionados.

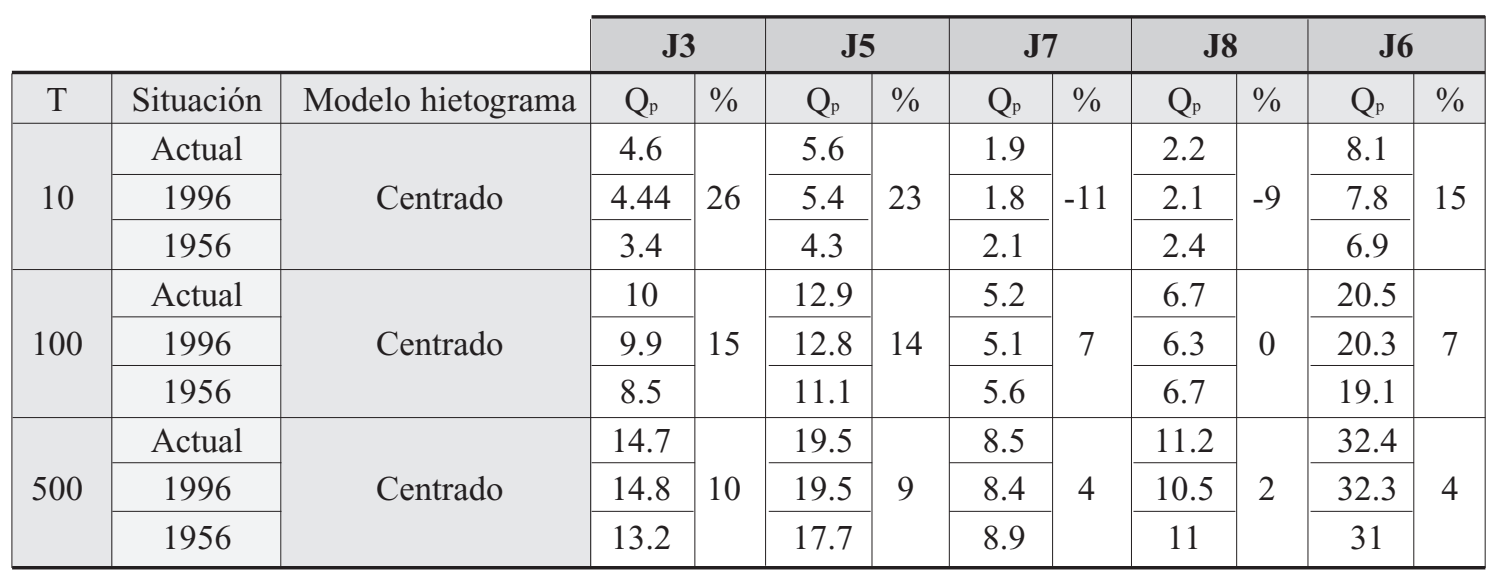

Dónde: $\mathrm{Q}_{\mathrm{p}}=$ caudales punta $\left(\mathrm{m}^{3} \mathrm{~s}^{-1}\right) . \%=$ porcentaje de cambio entre las situaciones de $1956 \mathrm{y}$ actual. J3 = punto de control en el barranco de Portainé donde se han producido los cambios más significativos en los usos del suelo. J5= punto de control situado aguas abajo del J3 en el barranco de Portainé. J7 = punto de control situado en el barranco de Reguerals. J8= punto de control situado aguas debajo de J7 en el barranco de Reguerals. J6 = Punto de control situado en la desembocadura de los barrancos de Portainé y Reguerals.

Tabla 8. Resumen de los porcentajes de cambio de Qp producidos entre la situación de 1956 y la actual, para distintos periodos de retorno.

\begin{tabular}{|c|c|c|c|c|}
\cline { 3 - 5 } \multicolumn{1}{c|}{} & T10 & T100 & T500 \\
\hline \multirow{2}{*}{ Portainé } & J3 & $26 \%$ & $15 \%$ & $10 \%$ \\
\cline { 2 - 5 } & J5 & $25 \%$ & $14 \%$ & $9 \%$ \\
\hline \multirow{2}{*}{ Reguerals } & J7 & $-9 \%$ & $7 \%$ & $4 \%$ \\
\cline { 2 - 5 } & J8 & $-11 \%$ & $0 \%$ & $2 \%$ \\
\hline \multirow{2}{*}{ J6 "Desembocadura" } & $15 \%$ & $7 \%$ & $4 \%$ \\
\hline
\end{tabular}

En general se detectan mayores diferencias en el T10, debido sobre todo a la influencia que tiene la cobertura del suelo (y por lo tanto el CN) en periodos de retorno bajos, con magnitudes de lluvia también bajos.

Mientras que para los T100 y T500 las diferencias se atenúan, debido a que la respuesta hidrológica a las grandes magnitudes de precipitaciones no está tan influenciadas por las coberturas, ya que superan ampliamente el umbral de escorrentía, sea cual fuere.

El punto de control J3, es el que más ha visto aumentado su Qp con un $26 \%$, respecto a la T10, coincidiendo con el mayor aumento en la superficie de pistas de esquí en los últimos años. Mientras que en Regerals en el punto J8 se observa una reducción de hasta un $11 \%$, pudiendo ser debida a un aumento de la cobertura de bosque. Pero en términos generales se observa un aumento del Qp en el punto J6 ó "Desembocadura" de un 15\%, siempre teniendo en cuenta el periodo de retorno de 10 años, que ha mostrado mayor influencia por las variaciones en los usos y ocupación del suelo. 


\subsubsection{Comparación de los Qp en distintos años y T}

En la figura 8, se muestran las diferencias entre los distintos $\mathrm{Q}_{\mathrm{p}}$, a la salida de la cabecera de Portainé (Junction 6), de los periodos de retorno estudiados. Como se puede observar, para una frecuencia o período de retorno dado, el caudal correspondiente para la situación actual es siempre mayor que el de 1956. Dicho de otro modo, dado un caudal, su período de retorno es menor (frecuencia es mayor) para la situación actual.

En conclusión esta figura muestra el aumento de la frecuencia y de las magnitudes de los $\mathrm{Q}_{\mathrm{p}}$ para los mismos periodos de retorno de las situaciones pasadas.

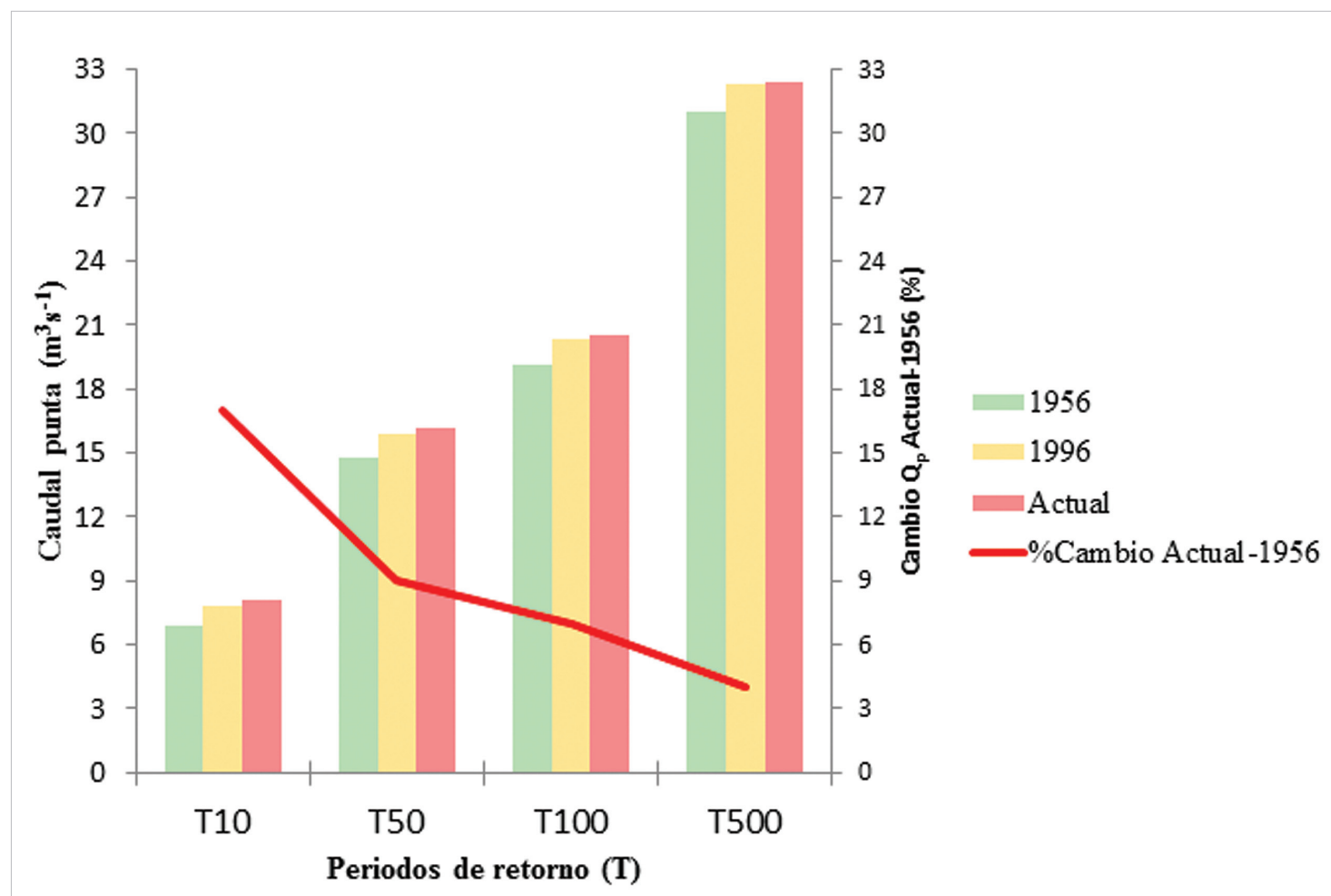

Figura 8. Variaciones de los caudales punta de los diferentes T para las situaciones actual, 1996, y 1956.

\subsection{Interpretación y recomendaciones técnicas}

Analizados los resultados y problemática de la zona, se recomienda:

- Completar y continuar los estudios:

Mediante la instalación de estaciones meteorológicas y mantenimiento de las estaciones ya presentes para poder obtener una serie representativa de las precipitaciones en la zona. También se aconseja la instalación de instrumental hidrológi- 
co (aforos) y la correlación con modelos hidráulicos, para poder estudiar si hubo un efecto umbral que desencadenó la inestabilización del barranco y el aumento de la frecuencia de los debris.

- Compensar y corregir las variaciones antrópicas en la respuesta hidrológica:

a) Medidas naturales de retención de agua en el territorio, como por ejemplo favorecer el desarrollo del rododendro, revegetando con pastizal bien desarrollado o la descompactación de los suelos (caminos, pistas, terraplenes...).

b) Medidas estructurales, como la construcción de tanques de tormenta, balsas de laminación o sistemas de drenajes, que no concentren el agua en unos pocos sino que la distribuyan, o incluso evacuando el agua a otros barrancos, disipando el efecto de creación de cárcavas en este lugar en concreto.

\section{Conclusiones}

- Las modificaciones antrópicas en los usos y ocupación del suelo en la cabecera del barranco de Portainé a lo largo de las últimas décadas han modificado su respuesta hidrológica.

- No se han producido cambios significativos entre los modelos de cuenca actuales y los de las situaciones pasadas, a excepción de la construcción de una balsa central en 2010, que modifica levemente la disposición del flujo de agua en sus proximidades.

- Se han producidos cambios significativos en los números de curva entre las situaciones de 1956 y la actual, fundamentalmente en la zona donde se ha instalado la estación de esquí, con aumentos de entre el 9 y el 12\% entre las dos situaciones, mientras que en el resto de la cabecera no ha habido cambios relevantes.

- Se ha comprobado mediante un estudio de sensibilidad la importancia de los valores del CN en la zona, ya que pequeños cambios del 10\% de estos valores, pueden provocar aumentos del $30 \%$ en los caudales punta.

- La variación de caudales punta generados en eventos extremos puede alcanzar hasta un $26 \%$ más de caudal entre la situación de 1956 y la actual, para la cabecera y periodo de retorno de 10 años; y hasta un $15 \%$ más de caudal para la confluencia con el barranco de Reguerals.

- Estas modificaciones hídricas han podido contribuir significativamente al desencadenamiento de fenómenos torrenciales y de movilización de carga sólida por desestabilización de los cauces y sus márgenes en la última década.

- Se ha demostrado el efecto significativo que han tenido los cambios en los usos y ocupación del suelo acaecidos en la cabecera de Portainé en las últimas décadas, como consecuencia de la construcción de la estación de esquí 
y la reducción de cobertura de arbusto rododendro, capaces de retener mayor cantidad de agua de precipitación, y el aumento de la superficie desnuda, con menor capacidad de retener agua, haciendo que haya mayor escorrentía y esta se concentre en los canales de desagües, pudiéndose explicar la problemática de arrastre de materiales, erosión y desperfectos provocados en la estación de esquí y en las carreteras de acceso a esta.

- Para la prevención de riesgos y minimización de los daños se propone un doble paquete de actuaciones, que van desde la compensación o corrección de la respuesta hidrológica con medidas naturales de retención de agua en el territorio; hasta la adopción de actuaciones estructurales puntuales de corrección del drenaje y laminación de puntas, previo estudio coste-beneficio.

\section{Bibliografía}

Bodoque, J. M. (2012). Creación de un modelo de cuenca utilizando HEC-GeoHMS. En: Universidad de Castilla La Mancha, 2012.

Bodoque, J.M., Díez-Herrero, A., De Pedraza, J., Martín, J.F. y Olivera, F. (2006). Estimación de la carga sólida en avenidas de derrubios mediante modelos geomecánicos, hidrológicos e hidráulicos combinados: Venero Claro (Ávila). En: Pérez Alberti, A. y López Bedoya, J. (eds.), Geomorfología y territorio. Actas de la IX Reunión Nacional de Geomorfología, Santiago de Compostela, 13-15 de septiembre de 2006. Cursos y Congresos, 171, 483-495, Universidad de Santiago de Compostela, 1037 pp.

Chow, V.T.; Maidment, D.R.; Mays, L.W. (1994) Manual Hidrología Aplicada. McGrawHill, Bogotá.

Díez-Herrero, A. (2002). Condicionantes geomorfológicos de las avenidas y cálculo de caudales y calados. En: Ayala-Carcedo, F.J. y Olcina Santos J. (Coords.), Riesgos Naturales. Cap. 49, págs. 921-952, Editorial Ariel, Ariel Ciencia, 1ª edición, Barcelona, 1512 pp.

Díez-Herrero, A.; Laín-Huerta, L. y Llorente-Isidro, M. (2008). Mapas de peligrosidad por avenidas e inundaciones. Guía metodológica para su elaboración. Publicaciones del Instituto Geológico y Minero de España, Serie Riesgos Geológicos/Geotecnia n ${ }^{0} 1,190$ págs., Madrid. D.L. M-46538-2008; ISBN 978-84-7840-770-5; NIPO 657-08-026-2.

Ferrer, F. J. (1993) Recomendaciones para el Cálculo Hidrometeorológico de Avenidas. En: CEDEX, Ministerio de Obras Públicas, Madrid, 75 pp.

Ferrer, M., González de Vallejo, L.I., García López-Davalillo, J.C., Rodríguez, J.A., Estévez, H., Trimboli, M. (2004). Pérdidas por terremotos e inundaciones en España durante el periodo 1987-2001 y su estimación para los próximos 30 años (2004-2033). Instituto Geológico y Minero de España y Consorcio de Compensación de Seguros, Madrid, 126 pp. D.L. M-51.694-2004.

Ferrer, (2003). "Análisis de Nuevas Fuentes de Datos para la Estimación del Parámetro Número de Curva del Modelo Hidrológico del SCS". Cuadernos de Investigación CEDEX. C48. 2003.

Fread, D. and Lewis J. 1998. NWS FLDWAV Model. Theoretical Description and User Documentation. National Weather Service. 
Furdada, G., Génova, M., Guinau, M., Victoriano, A., Khazaradze, G., Díez-Herrero, A., Calvet, J. (2016). Las avenidas torrenciales de los barrancos de Portainè, Reguerals y Ramiosa (Pirineo Central): evolución de las cuencas y dinámica torrencial. Editado por: J.J. Duran, Montes, M., Robador, A. Y Salazar, A. En. Madrid: Publicaciones del Instituto Geológico y Minero de España, Geología y Geofísica, 2016. 315-322 p.

HEC (2015). Hydrologic Modeling System HEC-HMS. User's Manual, v.4.1. Hydrologic Engineering Center, US Army Corps of Engineers, 584 pp.

IGC (Instituto Geológico de Cataluña, 2013). Evaluación de la dinámica torrencial del torrente de Portainé. En. Barcelona: Generalitat de Cataluña, 2013, vol. 2.

Llorente Isidro, M.; Díez-Herrero, A.; Laín-Huerta, L. y Ballesteros Canovas, J.A. (2008). La peligrosidad de avenidas torrenciales e inundaciones en PRIGEO. En: I. Galindo Jiménez, L. Laín Huerta y M. Lorente Isidro (Eds.), El estudio y la gestión de los riesgos geológicos. Publicaciones del Instituto Geológico y Minero de España, Serie: Medio Ambiente. Riesgos Geológicos, $\mathrm{n}^{\circ}$ 12, Capítulo 1, 13-20, Madrid, IGME y Consorcio de Compensación de Seguros (MEH). ISBN: 978-84-7840-755-2; NIPO: 657-08022-0; D.L. M-15342-2008.

Llorente Isidro, M.; Díez-Herrero, A. y Laín-Huerta, L. (2009). Aplicaciones de los SIG al análisis y gestión del riesgo de inundaciones: avances recientes. Cuadernos de la Sociedad Española de Ciencias Forestales, 29 "Actas I Jornadas Técnicas SIGTEFOR", 29-37 y 97-99. ISSN: 1575-2410

Luis-Fonseca, R., Raïmat, C., Hürlimann, M., Abancó, C., Moya, J., Fernández, J. (2011). Debris-flow protection in recurrent areas of the Pyrenees. Experience of the VX systems from output results collected in the pioneermonitoring station in Spain. Italian Journal of Engineering Geology and Environment: 1063-1071. DOI: 10.4408/IJEGE. 2011-03.B-115.

Ministerio de Fomento, (2016). Orden FOM/298/2016, de 15 de febrero, por la que se aprueba la norma 5.2 -IC drenaje superficial de la Instrucción de Carreteras. Boletín Oficial del Estado., Jueves 10 de marzo de 2016. 2016, 60(Sección I), 18882-18918.

NRCS (2004)a. Hydrologic Soil-Cover Complexes.

NRCS (2004)b. National Engineering Handbook. Part 630: Hydrology, chapter 10. National Resources Conservation Service.

NRCS (2007). National Engineering Handbook. Part 630: Hydrology, chapter 7: Hydrologic Soil Groups.

Portilla, M., Chevalier, G., Hürlimann, M. (2010). Description and analysis of the debris flows occurred during 2008 in the Eastern Pyrenees. Natural Hazards and Earth System Sciences 10: 1635-1645.

Raïmat, C., Riera, E., Graf, Ch., Luis-Fonseca, R., Fañanás, C., Hürlimann, M. (2013). Experiencia de la aplicación de RAMMS para la modelización de flujo tras la aplicación de las soluciones flexibles VX en el barranco de Portainé. En: Libro del VIII Simp. Nac. Sobre Taludes y Laderas In- estables, Palma de Mallorca, 11-14 Junio 2013. CIMNE, Barcelona, 1131-1144.

Salas, L. (2005). Regionalización de leyes IDF para el uso de modelos hidrometeorológicos de estimación de caudales. politécnica de Madrid.

Salas, L. y Fernández, J. A. (2006). Nueva metodología para el análisis de la variable Intensidad Máxima Anual de Precipitación. Ecología, 2006, 20, 435-444.

Salas, L. y Carrero, L.; (2006). Estimación de la precipitación máxima anual para una dura- 
ción y periodo de retorno determinados en la España peninsular mediante la aplicación informática MAXIN. E.U. Ingeniería Técnica Forestal (UPM). Madrid. http://www.eco gesfor.org/restauracion/MAXIN_v2/MAXIN/APLICACION/principal.html (última visita 21-07-2016)

SCS (Soil Conservation Service) (1972): National Engineering Handbook, Section 4. U.S. Department of Agriculture, Washington, D.C.

Victoriano, A., Guinau, M., Furdada, G., Calvet, J., Cabré, M., Moysset, M. (2016). Aplicación de datos LiDAR en el estudio de la dinámica torrencial y evolución de los barrancos de Portainé y Reguerals (Pirineos Centrales). Editado por: J.J. Duran, Montes, M., Robador, A. Y Salazar, A. En. Madrid: Publicaciones del Instituto Geológico y Minero de España, Geología y Geofísica, 2016. 447-455 p. 
De las Heras, A. | Cuad. Soc. Esp. Cienc. For. 43 (2017) 239-264 